\title{
Treatment outcome of extra-pulmonary tuberculosis in Finland: a cohort study
}

\author{
Tuula Vasankari*1,2, Pekka Holmström', Jukka Ollgren', Kari Liippo² and Petri Ruutu
}

\begin{abstract}
Background: We investigated the treatments given, the outcome and the patient- and treatment-system dependent factors affecting treatment outcome in a national two-year cohort of culture-verified extra-pulmonary tuberculosis cases in Finland.

Methods: Medical records of all cases in 1995 - 1996 were abstracted to assess treatment and outcome, using the European recommendations for outcome monitoring. For risk factor analysis, outcome was divided into three groups: favourable, death and other unfavourable. Predictors of unfavourable outcome were assessed in univariate and multivariate analysis.

Results: In the study cohort of 276 cases, 116 (42.0\%) were men and 160 (58.0\%) women. The mean age was 65.7 years. A favourable outcome was achieved in 157/276 (56.9\%) cases, consisting of those cured (8.0\%) and treatment completed (48.9\%). Death was the outcome in $17.4 \%$ (48/276) cases, including cases not treated. Other unfavourable outcomes took place in 45 (16.3\%) cases. Significant independent risk factors for death in multinomial logistic regression model were male sex, high age, immunosuppression, any other than a pulmonary specialty being responsible at the end of the treatment and other than standard combination of treatment. For other unfavourable treatment outcomes, significant risk factor was treatment with INH + RIF + EMB/SM. Deep site of TB was inversely associated with the risk of other unfavourable outcome.

Conclusions: The proportion of favourable outcome was far below the goal set by the WHO. Age and comorbidities, playing an important role in treatment success, are not available in routine outcome data. Therefore, comparisons between countries should be made in cohort analyses incorporating data on comorbidities.
\end{abstract}

\section{Background}

World Health Organization (WHO) has set the international target value for the favourable treatment outcome to be $85 \%$ [1]. WHO and the International Union Against Tuberculosis and Lung Disease (IUATLD) have published joint recommendations for assessing the outcome of tuberculosis treatment aiming at standardised reporting in Europe [2-5]. These recommendations are mainly designed for smear positive pulmonary tuberculosis treated with standard short course protocol, but they are commonly used for extra-pulmonary tuberculosis [6,7].

Many industrialized countries with comprehensive health care and a secure supply of drugs free of charge for patients have not reached the overall objective of $85 \%$

* Correspondence: tuula.vasankari@utu.fi

1 Department of Infectious Disease Surveillance and Control, National Institute for Health and Welfare, Mannerheimintie 166, 00300 Helsinki, Finland Full list of author information is available at the end of the article with successful outcome, set by WHO [6-17]. In the routine data collection of the European Union and Western European countries among previously untreated definite pulmonary TB cases in 2005, 79\% had a successful outcome, $6 \%$ died, $4 \%$ failed or continued treatment beyond 12 months and $10 \%$ were lost to follow up. In our recent cohort analysis of treatment outcome of culture-verified pulmonary tuberculosis the proportion with favourable outcome was only $65 \%$, in contrast to the overall WHO target of $85 \%$ [18].

There is limited information concerning countrywide treatment outcome and risk factors for unfavourable treatment outcome of extra-pulmonary tuberculosis in low incidence countries. A problem in assessing treatment outcome in extra-pulmonary tuberculosis is the diversity in the nature of disease depending on the site of disease. In Western Europe, successful outcome was reported for $81 \%$ in extra-pulmonary tuberculosis [19]. 
Most studies including extra-pulmonary cases have reported results combined with pulmonary cases $[7,10,20]$. In a Danish national cohort analysis, the proportion with favourable outcome in extra-pulmonary tuberculosis was $68 \%$ [6].

Our aim was to find out how extra-pulmonary tuberculosis is treated, as well as determine the treatment outcome in Finland. We analyzed the risk factors, including the patient and treatment system dependent factors, for unfavorable treatment outcome of extra-pulmonary tuberculosisin a national, population-based two-year cohort of all culture-verified extra-pulmonary tuberculosis cases to establish a basis for improving treatment outcome results.

\section{Methods}

\section{Study cohort, case definitions and data collection}

The method of identifying all culture-confirmed tuberculosis cases in Finland, with the first positive culture sample date between January $1^{\text {st }}$, 1995, to December $31^{\text {st }}$, 1996 ( $\mathrm{N}=1059)$, present in either the National Infectious Disease Register (NIDR) or acquired through a separate query to all microbiological laboratories has been described elsewhere [21].

A case of non-pulmonary tuberculosis was defined as culture finding for $M$. tuberculosis in other specimen type than respiratory secretion, in the absence of $M$. tuberculosis in culture from respiratory secretions and sputum smear positivity for acid fast bacilli $[18,22]$. With this definition, 322 (30\% of the whole cohort) constituted the base-frame for the extra-pulmonary tuberculosis cohort.

Out of the 322 cases in the extra-pulmonary tuberculosis cohort, complete medical records were available for 311 (96.6\%) (Figure 1). Among these 311 cases, four (1.3\%) had previously been treated for tuberculosis after the year 1970, and were excluded from the outcome anal-

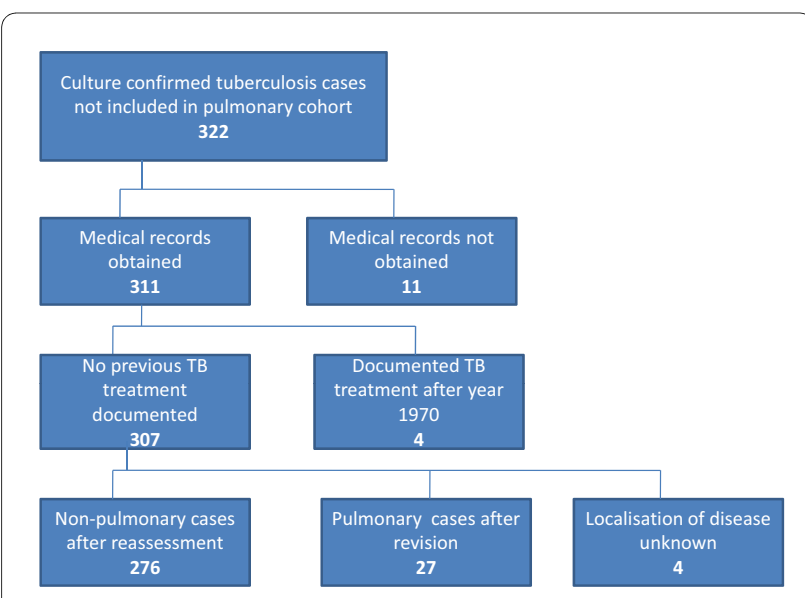

Figure 1 Composition of the national study cohort of cultureconfirmed extra-pulmonary tuberculosis cases.
Table 1: The composition of extra-pulmonary study cohort

\begin{tabular}{lcc}
\hline Form of tuberculosis & N & Percent \\
\hline Lymp node & 106 & 38.4 \\
\hline Skin & 13 & 4.7 \\
\hline Pleural & 50 & 18.1 \\
\hline Uninary and reproductive system & 60 & 21.7 \\
\hline Bone and joints & & \\
\hline Other & 20 & 7.3 \\
\hline Total & 27 & 9.8 \\
\hline
\end{tabular}

ysis as re-treatment cases. We further assessed the detailed clinical information in patient charts in order to divide the cases as deep and superficial disease. During this assessment we identified sample types not directly classifiable as pulmonary or non-pulmonary. All the patient charts and autopsy reports of this group of cases were assessed. We found 27 cases as having been erroneously classified by our original algorithm as extra-pulmonary TB. These cases were diagnosed from the culture of gastric aspirate or biopsy samples from lung tissue. In four cases the information was not sufficient for judging the location of the disease. These 31 cases were excluded from the extra-pulmonary study group leaving 276 extrapulmonary cases with no previous treatment documented (Table 1). These extra-pulmonary TB cases were divided to deep and superficial disease based on the site of bacteriological sampling and/or ICD-codes. Lymph node and skin tuberculosis were considered as superficial and other forms as deep extra-pulmonary disease. If the same patient had both deep and superficial disease, the case was classified as deep disease.

\section{Definitions of treatment}

Tuberculosis treatment was initiated in and supervised by the pulmonary departments of public hospitals in the great majority of cases. Chemotherapy combination was decided by the treating physician. In our retrospective record review, the combination actually given to each patient was grouped into six categories (Table 2) in order to describe the variability in treatment combinations used. Definitions for the grouping were based on the national recommendations in Finland following the recommendations by WHO, ATS and BTS [23-28]. We have previously described the treatment grouping in detail 
Table 2: Definitions used in describing the treatment given to the cases in a national cohort of patients with extrapulmonary tuberculosis

\begin{tabular}{|c|c|c|c|c|}
\hline Treatment group & Drugs used in intensive phase & $\begin{array}{l}\text { Duration of intensive } \\
\text { phase [days] }\end{array}$ & $\begin{array}{l}\text { Drugs used in } \\
\text { continuation phase }\end{array}$ & $\begin{array}{l}\text { Total duration of } \\
\text { treatment [months] }\end{array}$ \\
\hline Standard treatment $\mathrm{A}$ & isoniazid + rifampicin + pyrazinamide & At least 54 & isoniazid + rifampicin & At least 5 1/2 \\
\hline Standard treatment B & $\begin{array}{l}\text { isoniazid + rifampicin + ethambutol or } \\
\text { streptomycin }\end{array}$ & At least 54 & isoniazid + rifampicin & At least 8 \\
\hline $\begin{array}{l}\text { Standard treatment } \\
\text { with short intensive } \\
\text { phase } C\end{array}$ & $\begin{array}{l}\text { isoniazid + rifampicin + pyrazinamide } \\
\text { or ethambutol or streptomycin }\end{array}$ & Less than 54 & isoniazid + rifampicin & $\begin{array}{l}\text { At least } 51 / 2 \text { for } A \text { At least } \\
8 \text { for } B\end{array}$ \\
\hline Standard treatment D & $\begin{array}{l}>4 \text { tuberculosis drugs, including the } \\
\text { drugs in Standard treatment A or B }\end{array}$ & At least 54 & $\begin{array}{l}\text { isoniazid + rifampicin } \\
+ \text { any other anti- } \\
\text { tuberculosis drug(s) }\end{array}$ & $\begin{array}{l}\text { At least } 51 / 2 \text { for } A \text { At least } \\
8 \text { for } B\end{array}$ \\
\hline $\begin{array}{l}\text { Other combination of } \\
\text { tuberculosis drugs }\end{array}$ & $\begin{array}{l}\text { Non-standard combinations of } \\
\text { tuberculosis drugs, excluding the } \\
\text { combinations above }\end{array}$ & $\mathrm{NA}^{2}$ & $\begin{array}{l}\text { Any combination of } \\
\text { antituberculosis drugs }\end{array}$ & NA \\
\hline Ineffective treatment & $\begin{array}{l}\text { One antituberculosis drug used alone } \\
\text { or in combination with a drug with } \\
\text { limited antituberculosis activity }{ }^{1}\end{array}$ & NA & NA & NA \\
\hline
\end{tabular}

1E.g. fluoroquinolones

2NA $=$ not applicable

[18]. Pauses of chemotherapy were recorded only when lasting at least one week, and calculated only for standard treatments.

\section{Definitions of outcome}

The categories of WHO/EuroTB recommendation for outcome monitoring are cure, treatment completed, failure, death, treatment interrupted (default), transfer out, and on treatment at 12 months [5]. The duration of the follow up period is defined as 12 months from the beginning of the treatment or the date of diagnosis, and the first outcome registered as final.

The WHO/EuroTB category 'treatment interrupted' includes all interruptions, whether caused by a patient or by a treating physician. For analysing these two separately, we divided 'treatment interrupted' into 'physician's decision to stop early' and 'default' for interruptions due to patient only [18]. The outcome was recorded as 'death', if the case died before starting the treatment, during the treatment, or the date of death was within 14 days after cessation of the anti-TB drugs.

The outcome categories used are listed in Table 3. The outcome was categorized as favourable in cases of cure and treatment completed, and as unfavourable in cases of failure, death, default, physician's decision to stop early and transfer out.

\section{Definitions of origin, social and medical risk factors}

A case was defined as immigrant if the country of birth was not Finland or, in the absence of country of birth, the nationality was other than Finnish. Immunosuppressive treatment was defined as corticosteroid treatment ( $>40$ mg per day of any duration, or any daily dose with treatment duration exceeding one month), cytotoxic or cyclosporine treatment, or radiation therapy during the preceding year. For inclusion in the group of social risk factors, a case had a history of alcohol abuse, unemployment, imprisonment or homelessness recorded in patient records. To be included in the diabetes risk group the case had juvenile or adult onset disease on medication.

\section{Definitions of characteristics of treatment system}

Specialty responsible for treatment was that of the unit treating patient as an inpatient or outpatient.

\section{Ethical review}

The ethics approval for this study was acquired from the National Research and Development Centre for Welfare and Health.

\section{Statistical methods}

Median age comparisons where tested using Median test. For comparison of proportions, Chi-square or Fisher's 
Table 3: Summary of the outcome criteria used in the study

\begin{tabular}{ll}
\hline Indicator & Definition \\
\hline Cure & Treatment completion and: \\
& - culture becoming negative on samples \\
& taken at the end of treatment and on at least \\
& one previous occasion or \\
& - sputum microscopy becoming negative for \\
& AFB at the end of treatment and on at least \\
& one previous occasion.
\end{tabular}

\begin{tabular}{ll}
\hline $\begin{array}{l}\text { Treatment } \\
\text { completed }\end{array}$ & $\begin{array}{l}\text { Treatment completion, not meeting the } \\
\text { criteria to be classified as Cured or Failed }\end{array}$ \\
\hline Death & $\begin{array}{l}\text { Death before starting treatment or during } \\
\text { treatment, irrespective of cause. }\end{array}$ \\
\hline
\end{tabular}

\begin{tabular}{|c|c|}
\hline Transfer out & $\begin{array}{l}\text { Patient referred to another clinical unit for } \\
\text { treatment and final outcome unknown }\end{array}$ \\
\hline Failed & $\begin{array}{l}\text { Culture or sputum microscopy remaining } \\
\text { positive or becoming positive again at } 5 \\
\text { months or later during treatment. }\end{array}$ \\
\hline Default & $\begin{array}{l}\text { Treatment interrupted for } 2 \text { consecutive } \\
\text { months, or more for reasons due to patient. }\end{array}$ \\
\hline $\begin{array}{l}\text { Physician's } \\
\text { decision } \\
\text { to stop early }\end{array}$ & $\begin{array}{l}\text { Treatment interrupted for } 2 \text { consecutive } \\
\text { months, or more due to physician's decision. }\end{array}$ \\
\hline $\begin{array}{l}\text { On } \\
\text { treatment at } \\
12 \text { months }\end{array}$ & $\begin{array}{l}\text { Patient still on treatment at } 12 \text { months who } \\
\text { did not meet any other outcome during } \\
\text { treatment. This includes patients with: } \\
\text { - initial treatment changed due to } \\
\text { polyresistance (ie. resistance to at least two } \\
\text { first line drugs) on the isolate taken at the start } \\
\text { of treatment. } \\
\text { - treatment prolonged because of side } \\
\text { effects/complications } \\
\text { - initial regimen planned for }>12 \text { months } \\
\text { - information on the reasons for being still on } \\
\text { treatment not available }\end{array}$ \\
\hline Not known & $\begin{array}{l}\text { Information on outcome not available, for } \\
\text { cases not known to have been transferred }\end{array}$ \\
\hline
\end{tabular}

generalised exact test with Monte Carlo simulation was used. Stata 11.0 (StataCorp LP Texas, USA) and IBM SPSS for Windows, version 18.0.2 (Chicago, IL, USA) was used for statistical calculations. We used binary and multinomial logistic regression model to assess the relationships between all predictors that were found to be significant in pulmonary tuberculosis (to compare extra- pulmonary tuberculosis to pulmonary tuberculosis in respect to these variables), and other variables which in the univariate analysis had a p-value less than 0.20 , with binomial and trinomial outcome variables, in which the reference class was favourable outcome. To the final model, predictors were selected by forcing all those variables that were significant in pulmonary tuberculosis, and from other variables selection was by forward stepwise method. P-values under 5\% were considered as significant. For univariate results also Chi squared test and Fisher's exact test were used.

\section{Results}

In the study cohort of 276 cases, 116 (42.0\%) were men and $160(58.0 \%)$ women. The median age was 70.1 years. There were 170 cases aged $>65$ years $(61.6 \%)$. The proportion of immigrants was $10.9 \%$ (30 cases), mainly from developing countries. There were no cases of HIV-coinfection in the cohort. There was one prisoner in the study cohort.

\section{Treatment given}

Tuberculosis chemotherapy was given to 257 (93.1\%) of the 276 cases. Half of the cases $(140 / 257 ; 54.5 \%)$ received standard treatment A, 28 (10.9\%) received standard treatment $B$, and $30(11.7 \%)$ received standard treatment with additional drugs (D) (Table 4). In 18 (7.0\%) of the cases the intensive phase was short (category C). A total of 41 cases $(16.0 \%)$ received either other combinations of tuberculosis drugs or ineffective treatment. Most of the cases $(177 / 257,68.9 \%)$, were treated with the same combination during the whole treatment. Nineteen $(6.9 \%)$ of the 276 cases were untreated, the majority $(16 ; 84.2 \%)$ of whom died before the diagnosis of tuberculosis was established.

The median age differed significantly between the treatment groups; it was 70,5 (range 6,9-94,4) years for category A, $72.6(18,5-90,4)$ for category B, $58.2(6,6-91,0)$ for category C, $57.5(15,1-88,2)$ for category D, $72.6(60,8$ $71,6)$ for other combinations and $67.8(18,6-94,4)$ for ineffective treatment $(\mathrm{p}=0.005)$. There were $62(44.3 \%)$ men in treatment group A, 10 (35.7\%) in B, $6(33.3 \%)$ in C, 15 $(50.0 \%)$ in $\mathrm{D}, 8(22.2 \%)$ in other combinations and 4 $(80.0 \%)$ in ineffective treatment group. The difference was significant $(\mathrm{p}=0.04)$. There was no statistical difference between groups regarding the presence of a social risk factor $(\mathrm{p}=0.32)$.

\section{Outcome of treatment}

A favourable outcome was achieved in 157/276 (56.9\%) of the cases, consisting of those cured (8.0\%) and treatment completed (48.9\%). The proportion with favourable outcome varied between 35.7 to $80.0 \%$ in different treatment groups. There were no treatment failures in the cohort. 
Table 4: Treatment outcome in the study cohort of 276 extra-pulmonary tuberculosis cases according to the WHO/EuroTB classification, modified for 'default' and 'physician's decision to stop early'

\begin{tabular}{|c|c|c|c|c|c|c|c|c|c|c|c|}
\hline \multirow[t]{2}{*}{ Treatment group } & \multicolumn{4}{|c|}{ FAVOURABLE } & \multicolumn{3}{|c|}{ UNFAVOURABLE' } & \multirow[b]{2}{*}{ Subtotal } & \multirow{2}{*}{$\begin{array}{l}\text { On } \\
\text { treatment at } \\
12 \text { months }\end{array}$} & \multirow[t]{2}{*}{ Not known } & \multirow[t]{2}{*}{ Total } \\
\hline & Cured & $\begin{array}{l}\text { Treatment } \\
\text { completed }\end{array}$ & Subtotal & Death & Transfer out & Default & $\begin{array}{l}\text { Physician's decision } \\
\text { to stop early }\end{array}$ & & & & \\
\hline \multirow[t]{2}{*}{ Standard treatment A } & 15 & 82 & 97 & 18 & 0 & 3 & 14 & 35 & 7 & 1 & 140 \\
\hline & $10.7 \%$ & $58.6 \%$ & $69.3 \%$ & $12.9 \%$ & 0 & $2.1 \%$ & $10.0 \%$ & $25.0 \%$ & $5.0 \%$ & $0.7 \%$ & $100 \%$ \\
\hline \multirow[t]{2}{*}{ Standard treatment B } & 1 & 9 & 10 & 5 & 0 & 1 & 8 & 14 & 4 & 0 & 28 \\
\hline & $3.6 \%$ & $32.1 \%$ & $35.7 \%$ & $17.9 \%$ & & $3.6 \%$ & $28.6 \%$ & $50.0 \%$ & $14.3 \%$ & & $100 \%$ \\
\hline \multirow{2}{*}{$\begin{array}{l}\text { Standard treatment with short intensive } \\
\text { phase } C\end{array}$} & 0 & 14 & 14 & 1 & 0 & 0 & 2 & 3 & 1 & 0 & 18 \\
\hline & & $77.8 \%$ & $77.8 \%$ & $5.6 \%$ & & & $11.1 \%$ & $16.7 \%$ & $5.6 \%$ & & $100 \%$ \\
\hline \multirow[t]{2}{*}{ Standard treatment D } & 3 & 10 & 13 & 1 & 0 & 1 & 4 & 6 & & 0 & 30 \\
\hline & $10.0 \%$ & $33.3 \%$ & $43.3 \%$ & $3.3 \%$ & & $3.3 \%$ & $13.3 \%$ & $20.0 \%$ & $36.7 \%$ & & $100 \%$ \\
\hline \multirow[t]{2}{*}{ Other combination of tuberculosis drugs } & 3 & 16 & 19 & 6 & 1 & 5 & 3 & 15 & 1 & 1 & 36 \\
\hline & $8.3 \%$ & $44.4 \%$ & $52.7 \%$ & $16.7 \%$ & $2.8 \%$ & $13.9 \%$ & $8.3 \%$ & $41.7 \%$ & $2.8 \%$ & $2.8 \%$ & $100 \%$ \\
\hline \multirow[t]{2}{*}{ Ineffective treatment } & 0 & 4 & 4 & 1 & 0 & 0 & 0 & 1 & 0 & 0 & 5 \\
\hline & & $80.0 \%$ & $80.0 \%$ & $20.0 \%$ & & & & $20.0 \%$ & & & $100 \%$ \\
\hline \multirow[t]{2}{*}{ Overall outcome with any treatment } & 22 & 135 & 157 & 32 & 1 & 10 & 31 & 74 & 24 & 2 & 257 \\
\hline & & $52.5 \%$ & $61.1 \%$ & $12.5 \%$ & $0.4 \%$ & $3.9 \%$ & $12.1 \%$ & $28.8 \%$ & $9.3 \%$ & $0.8 \%$ & $100 \%$ \\
\hline \multirow[t]{2}{*}{ No treatment } & NA & NA & NA & 16 & 0 & & 0 & 19 & 0 & 0 & 19 \\
\hline & & & & $84.2 \%$ & & $15.8 \%$ & & $100 \%$ & & & $100 \%$ \\
\hline \multirow[t]{2}{*}{ Total } & 22 & 135 & 157 & 48 & 1 & 13 & 31 & 93 & 24 & 2 & 276 \\
\hline & $8.0 \%$ & $48.9 \%$ & $56.9 \%$ & $17.4 \%$ & $0.4 \%$ & $4.7 \%$ & $11.2 \%$ & $33.7 \%$ & $8.7 \%$ & $0.7 \%$ & $100 \%$ \\
\hline
\end{tabular}

${ }^{1}$ There were no failures in the cohort.

${ }^{2}$ The treating physician decided not to give any treatment. 
The proportion of cases defaulting or transferring out was $14 / 276$ (5.1\%), and of them 5/14 (35.7\%) were immigrants and 2/14 (14.3\%) had a social risk factor. In 31 (11.2\%) cases treatment was stopped prematurely by physician. Death was the outcome in $17.4 \%$ (48/276) cases, including cases not treated.

The proportion of cases with favourable outcome differed significantly between treatment groups $(P<0.001)$, and was smallest in treatment groups B and D $(35.7 \%$ and $43.3 \%)$. The proportion of deaths differed between groups, and was lowest in treatment group D (3.3\%). In the ineffective treatment group the proportion of deaths was higher $(20.0 \%$ versus $12.1 \%)$ than in the other combinations of TB drugs.

24 of the cases were still on treatment at 12 months, and in two cases it was not possible to judge the outcome from the information available. Of the remaining 250 cases, 19 were not treated, among them 11 (57.9\%) were men and $8(42.1 \%)$ women. Of this group, with a median age of 81.0 years, 16 died before treatment and 3 were left untreated. These 45 cases were excluded from the analysis of risk factors of poor treatment outcome.

\section{Analysis of risk factors for unfavourable outcome}

In univariate analysis, patient-related risk factors which were significantly associated $(\mathrm{p}<0.05)$ with death, were high age, immunosuppression and diabetes (Table 5). Treatment system -related risk factors which were significantly associated with death were the specialty of the treating unit (internal medicine, general medicine in primary care), change of specialty responsible for treatment and less than five treated cases per year per unit (Table 6). There was no statistically significant patient-related personal risk factor association for other unfavourable outcome (i.e. transfer out, default or physician's decision to stop early) (Table 5). Treatment system -related significant risk factors for other unfavourable outcome were standard treatment $\mathrm{B}$, other treatment combination, change in treatment group and pause(s) during treatment (Table 6). For all unfavourable outcomes together, i.e. death and other unfavourable outcome combined, significant predictors in univariate analysis were high age, immunosuppression, specialty of the treating unit (general medicine in primary care), change of specialty responsible for treatment, less than five treated cases per year per unit, standard treatment B, other treatment combination and pause(s) during treatment.

Significant independent risk factors for death in multinomial logistic regression model were male sex, high age, immunosuppression, any other than a pulmonary specialty being responsible at the end of the treatment and other than standard combination of treatment. For other unfavourable treatment outcomes, significant risk factor was treatment group B (Table 7). Deep site of TB was inversely associated with the risk of other unfavourable outcome $(\mathrm{p}=0.02)$.

For death and other unfavourable outcomes together, significant risk factors in the binary logistic regression model were high age $(\mathrm{p}=0.02)$, immunosuppression $(\mathrm{p}=$ $0.001)$, treatment group $B(p<0.001)$ and any other than a pulmonary, internal and general medicine specialty being responsible at the end of the treatment $(p=0.01)$. Almost significant risk factors were male sex $(p=0.06)$ and specialty of the treating unit (general medicine in primary care $)(p=0.06)$. Deep site of tuberculosis was almost significantly protective $(\mathrm{p}=0.07)$ (Table 7$)$.

When we analysed all 250 cases in the cohort with known outcome, including those 19 without treatment, the associations observed in multivariate analysis as significant were the same as with the 231 cases of the presented analysis.

\section{Discussion}

In a two-year national cohort of culture-confirmed extrapulmonary tuberculosis cases, we observed a favourable outcome of treatment in 57\%, far less than the target level presented by WHO for favourable outcomes. High death rate, physician's decision to stop the treatment too early and treatment still going on at 12 months were the main reasons.

The proportion of favourable outcome in our extra-pulmonary tuberculosis cohort was even smaller than for culture- proven pulmonary tuberculosis during the same time period [18]. Our proportion with favourable outcome was smaller than that in a Danish national cohort analysis, where the proportion of favourable outcome in extra-pulmonary tuberculosis was $68 \%$ [6], or the $81 \%$ reported for extra-pulmonary tuberculosis in the routine surveillance data collection of the European Union and other Western European countries [19]. In a number of studies combining outcome in pulmonary and extra-pulmonary cases, the proportions with favorable treatment outcomes have ranged between 68 - 82\% [7,10,20], and are not comparable to our current figures. The large proportion of lymph node and skin manifestations in extrapulmonary tuberculosis, for the outcome of which the impact from systemic chemotherapy may be different from pulmonary and deep extra-pulmonary tuberculosis, warrants separate assessment of the outcome of extrapulmonary tuberculosis.

The outcome analysis recommended by WHO and the International Union Against Tuberculosis and Lung Disease (IUATLD) is mainly developed for smear or culture positive pulmonary disease. It can be used in extra-pulmonary disease, but due to the great diversity in the clinical presentation of extra-pulmonary disease and treatment regimens used, it might need development for this purpose. For example, in TB meningitis, the pro- 
Table 5: Univariate analysis of the association of patient -related characteristics with an unfavourable outcome in 231 cases treated for at least 24 hours

\begin{tabular}{|c|c|c|c|c|c|c|c|c|c|c|c|}
\hline \multirow[t]{2}{*}{ Variable } & & \multirow{2}{*}{$\begin{array}{l}\text { Total } \\
\mathbf{N}\end{array}$} & \multicolumn{3}{|c|}{ Death } & \multicolumn{3}{|c|}{ Other unfavourable } & \multicolumn{3}{|c|}{ All unfavourable (death and other) together } \\
\hline & & & $\mathbf{N}$ & OR $(95 \% \mathrm{Cl})$ & $\mathbf{p}$ & $\mathbf{N}$ & OR (95\% Cl) & $\mathbf{p}$ & $\mathbf{N}$ & OR $(95 \% \mathrm{Cl})$ & $\mathbf{p}$ \\
\hline \multirow[t]{2}{*}{ Sex } & female & 137 & 15 & 1 & & 26 & 1 & & 41 & 1 & \\
\hline & male & 94 & 17 & $1.78(0.83-3.82)$ & 0.14 & 16 & $0.97(0.48-1.95)$ & 0.93 & 33 & $1.27(0.72-2.21)$ & 0.41 \\
\hline Age at diagnosis & risk per five years & & & $1.53(1.24-1.88)$ & $<0.001$ & & $1.07(0.95-1.21)$ & 0.29 & & $1.18(1.03-1.34)$ & 0.01 \\
\hline \multirow[t]{2}{*}{ TB history } & no & 200 & 30 & 1 & & 35 & 1 & & 65 & 1 & \\
\hline & yes & 31 & 2 & $0.41(0.09-1.83)$ & 0.24 & 7 & $1.23(0.49-3.11)$ & 0.67 & 9 & $0.85(0.37-1.95)$ & 0.70 \\
\hline \multirow[t]{2}{*}{ Social risk factor } & no & 215 & 31 & 1 & & 40 & 1 & & 71 & 1 & \\
\hline & yes & 16 & 1 & $0.36(0.05-2.83)$ & 0.33 & 2 & $0.55(0.12-2.56)$ & 0.45 & 3 & $0.47(0.13-1.67)$ & 0.25 \\
\hline \multirow[t]{2}{*}{ Site of tuberculosis } & superficial & 114 & 13 & 1 & & 26 & 1 & & 39 & 1 & \\
\hline & deep & 117 & 19 & $1.34(0.62-2.89)$ & 0.46 & 16 & $0.56(0.28-1.13)$ & 0.11 & 35 & $0.82(0.47-1.43)$ & 0.48 \\
\hline \multirow[t]{2}{*}{ Immunosuppression } & no & 204 & 22 & 1 & & 38 & 1 & & 60 & 1 & \\
\hline & yes & 27 & 10 & $5.03(2.00-12.87)$ & 0.001 & 4 & $1.17(0.36-3.78)$ & 0.80 & 14 & $2.58(1.15-5.83)$ & 0.02 \\
\hline \multirow[t]{2}{*}{ Malignancy' } & no & 223 & 29 & 1 & & 42 & 1 & & 71 & 1 & \\
\hline & yes & 7 & 2 & $2.02(0.38-10.9)$ & 0.41 & 0 & 0 & 1.00 & 2 & $0.84(0.16-4.46)$ & 0.84 \\
\hline \multirow[t]{2}{*}{ Diabetes } & no & 205 & 25 & 1 & & 37 & 1 & & 62 & 1 & \\
\hline & yes & 26 & 7 & $2.86(1.05-7.79)$ & 0.04 & 5 & $1.38(0.47-4.08)$ & 0.56 & 12 & $1.98(0.86-4.52)$ & 0.11 \\
\hline Total & & 231 & 32 & & & 42 & & & 74 & & \\
\hline
\end{tabular}


Table 6: Univariate analysis of the association of treatment system -related characteristics with an unfavourable outcome in 231 cases treated for at least 24 hours

\begin{tabular}{|c|c|c|c|c|c|c|c|c|c|c|c|}
\hline \multirow[t]{2}{*}{ Variable } & & \multirow{2}{*}{$\begin{array}{l}\text { Total } \\
\text { N } \\
\end{array}$} & \multicolumn{2}{|c|}{ Death } & \multicolumn{4}{|c|}{ Other unfavourable } & \multicolumn{3}{|c|}{ All unfavourable (death and other) together } \\
\hline & & & $\mathbf{N}$ & OR $(95 \% \mathrm{Cl})$ & $\mathbf{p}$ & $\mathbf{N}$ & OR $(95 \% \mathrm{Cl})$ & $\mathbf{p}$ & $\mathbf{N}$ & OR $(95 \% \mathrm{Cl})$ & $\mathbf{p}$ \\
\hline \multirow[t]{4}{*}{ Specialty responsible for starting treatment } & pulmonary & 185 & 18 & 1 & & 34 & 1 & & 52 & 1 & \\
\hline & internal medicine & 33 & 9 & $3.50(1.38-8.90)$ & 0.009 & 5 & $1.02(0.36-2.96)$ & 0.96 & 14 & $0.43(0.06-2.97)$ & 0.39 \\
\hline & general medicine & 2 & 2 & $\operatorname{lnf}^{3}$ & 1.00 & 0 & 1.05 & 1.00 & 2 & $0.23(0.04-1.20)$ & 0.08 \\
\hline & other & 11 & 3 & $4.43(0.98-20.14)$ & 0.05 & 3 & $2.35(0.53-10.31)$ & 0.26 & 6 & $0.61(0.12-2.10)$ & 0.37 \\
\hline \multirow[t]{4}{*}{ Specialty responsible for ending treatment } & pulmonary & 161 & 8 & 1 & & 34 & 1 & & 42 & 1 & \\
\hline & internal medicine & 29 & 7 & $6.13(1.97-19.05)$ & 0.002 & 5 & $1.03(0.35-2.99)$ & 0.96 & 12 & $2.00(0.88-4.53)$ & 0.10 \\
\hline & general medicine & 35 & 16 & $14.00(5.21-37.65)$ & $<0.001$ & 2 & $0.41(0.09-1.87)$ & 0.25 & 18 & $3.00(1.42-6.35)$ & 0.004 \\
\hline & other & 6 & 1 & $3.72(0.37-37.29)$ & 0.26 & 1 & $0.41(0.09-8.09)$ & 0.91 & 2 & $1.42(0.25-8.02)$ & 0.69 \\
\hline \multirow{2}{*}{$\begin{array}{l}\text { Change of specialty responsible for } \\
\text { treatment }\end{array}$} & no & 174 & 16 & 1 & & 32 & 1 & & 48 & 1 & \\
\hline & yes & 57 & 16 & $4.06(1.83-9.02)$ & 0.001 & 10 & $1.27(0.56-2.86)$ & 0.58 & 26 & $2.20(1.19-4.09)$ & 0.01 \\
\hline \multirow{4}{*}{$\begin{array}{l}\text { Number of cases per year for unit responsible } \\
\text { for ending treatment }\end{array}$} & $1-4$ & 55 & 16 & $4.37(1.86-10.28)$ & 0.001 & 10 & $1.49(0.63-3.50)$ & 0.36 & 26 & $2.51(1.30-4.84)$ & 0.006 \\
\hline & $5-10$ & 12 & 1 & $0.88(0.10-7.56)$ & 0.91 & 2 & $0.96(0.19-4.76)$ & 0.96 & 3 & $0.93(0.24-3.64)$ & 0.92 \\
\hline & $11-29$ & 34 & 3 & $1.03(0.27-3.96)$ & 0.96 & 8 & $1.50(0.59-3.80)$ & 0.39 & 11 & $1.34(0.59-3.03)$ & 0.49 \\
\hline & $30-$ & 129 & 12 & 1 & & 22 & 1 & & 34 & 1 & \\
\hline
\end{tabular}


Table 6: Univariate analysis of the association of treatment system -related characteristics with an unfavourable outcome in 231 cases treated for at least 24 hours

\begin{tabular}{|c|c|c|c|c|c|c|c|c|c|c|c|}
\hline \multirow[t]{6}{*}{ Treatment group } & \multirow{2}{*}{$\begin{array}{l}\text { standard } \\
\text { treatment A } \\
\text { standard } \\
\text { treatment B }\end{array}$} & \multirow{2}{*}{$\begin{array}{l}132 \\
24\end{array}$} & \multirow{2}{*}{$\begin{array}{l}18 \\
5\end{array}$} & \multicolumn{2}{|l|}{1} & \multirow{2}{*}{$\begin{array}{l}17 \\
9\end{array}$} & \multicolumn{2}{|l|}{1} & \multirow{2}{*}{$\begin{array}{l}35 \\
14 \\
\end{array}$} & \multicolumn{2}{|l|}{1} \\
\hline & & & & $2.69(0.82-8.82)$ & 0.10 & & $5.14(1.82-14.49)$ & 0.002 & & $3.88(1.58-9.53)$ & 0.003 \\
\hline & $\begin{array}{l}\text { standard } \\
\text { treatment } C\end{array}$ & 17 & 1 & $0.40(0.05-3.11)$ & 0.37 & 2 & $0.82(0.17-3.91)$ & 0.80 & 3 & $0.59(0.16-2.19)$ & 0.43 \\
\hline & $\begin{array}{l}\text { standard } \\
\text { treatment D }\end{array}$ & 19 & 1 & $0.41(0.05-3.37)$ & 0.41 & 5 & $2.19(0.69-6.95)$ & 0.18 & 6 & $1.28(0.45-3.62)$ & 0.64 \\
\hline & $\begin{array}{l}\text { other } \\
\text { combination }\end{array}$ & 34 & 6 & $1.70(0.60-4.84)$ & 0.32 & 9 & $2.70(1.05-6.96)$ & 0.04 & 15 & $2.19(1.00-4.77)$ & 0.049 \\
\hline & ineffective & 5 & 1 & $1.35(0.14-12.76)$ & 0.80 & 0 & 0 & 1.00 & 1 & $0.69(0.07-6.41)$ & 0.74 \\
\hline \multirow[t]{2}{*}{ Change in treatment group } & no & 159 & 22 & 1 & & 22 & 1 & & 44 & 1 & \\
\hline & yes & 72 & 10 & $1.00(0.43-2.34)$ & 0.99 & 20 & $2.12(1.05-4.27)$ & 0.04 & 30 & $1.56(0.87-2.80)$ & 0.13 \\
\hline \multirow[t]{2}{*}{ Pause of treatment } & no & 169 & 25 & 1 & & 22 & 1 & & 47 & 1 & \\
\hline & yes & 62 & 7 & $0.98(0.39-2.45)$ & 0.96 & 20 & $3.17(1.55-6.46)$ & 0.002 & 27 & $2.00(1.09-3.66)$ & 0.02 \\
\hline \multirow[t]{2}{*}{ Pause during intensive phase ${ }^{1}$} & no & 183 & 25 & 1 & & 24 & 1 & & 49 & 1 & \\
\hline & yes & 47 & 6 & $1.40(0.52-3.78)$ & 0.51 & 18 & $4.37(2.05-9.29)$ & $<0.001$ & 24 & $2.88(1.43-5.78)$ & 0.003 \\
\hline \multirow{2}{*}{$\begin{array}{l}\text { Pause during intensive phase, due to side } \\
\text { effect }\end{array}$} & no & 191 & 26 & 1 & & 27 & 1 & & 53 & 1 & \\
\hline & yes & 40 & 6 & $1.68(0.61-4.60)$ & 0.32 & 15 & $4.04(1.82-8.92)$ & 0.001 & 21 & $2.85(1.48-5.51)$ & 0.002 \\
\hline Pause during continuation phase & no & 171 & 12 & 1 & & 25 & 1 & & 37 & 1 & \\
\hline
\end{tabular}


Table 6: Univariate analysis of the association of treatment system -related characteristics with an unfavourable outcome in 231 cases treated for at least 24 hours

\begin{tabular}{|c|c|c|c|c|c|c|c|c|c|c|c|}
\hline & yes & 34 & 2 & $1.12(0.23-5.36)$ & 0.89 & 12 & $3.22(1.40-7.40)$ & 0.006 & 14 & $2.53(1.17-5.50)$ & 0.02 \\
\hline & $\begin{array}{l}\text { NA (other + } \\
\text { ineffective) }\end{array}$ & 26 & 18 & & & 5 & & & 23 & & \\
\hline Total & & 231 & 32 & & & 42 & & & 74 & & \\
\hline
\end{tabular}

Significant p-values are darkened.

${ }^{1}$ Information missing for one case

${ }^{2}$ Information missing for 3 cases

${ }^{3}$ Max likelihood estimate is not finite. 
Table 7: Multivariate analysis of 231 cases treated at least 24 hours, odds ratio for death or other unfavourable (transfer out, default, physician's decision to stop early) outcomes.

\begin{tabular}{|c|c|c|c|c|c|c|c|c|c|c|}
\hline \multirow[t]{2}{*}{ Variable } & & \multicolumn{3}{|c|}{ Death } & \multicolumn{3}{|c|}{ Other unfavourable } & \multicolumn{3}{|c|}{ All unfavourable (death and other) together } \\
\hline & & $\mathbf{N}$ & OR $(95 \% \mathrm{Cl})$ & $\mathbf{p}$ & $\mathbf{N}$ & OR $(95 \% \mathrm{Cl})$ & $\mathbf{p}$ & $\mathbf{N}$ & OR $(95 \% \mathrm{Cl})$ & $\mathbf{p}$ \\
\hline \multirow[t]{2}{*}{ Sex } & female & 15 & 1 & & 26 & 1 & & 41 & 1 & \\
\hline & male & 17 & $8.53(3.23-22.50)$ & $<0.001$ & 16 & $1.24(0.55-2.84)$ & 0.61 & 33 & $2.04(0.98-4.24)$ & 0.06 \\
\hline Age at diagnosis & risk per five years & & $1.10(1.06-1.14)$ & $<0.001$ & & $1.01(0.98-1.04)$ & 0.30 & & $1.16(1.03-1.31)$ & 0.02 \\
\hline \multirow[t]{2}{*}{ Immunosuppression } & no & 22 & 1 & & 38 & 1 & & 60 & 1 & \\
\hline & yes & 10 & $5.58(1.92-16.21)$ & 0.002 & 4 & $1.22(0.38-3.90)$ & 0.74 & 14 & $2.07(1.33-3.22)$ & 0.001 \\
\hline \multirow[t]{2}{*}{ TB history } & no & 30 & 1 & & 35 & 1 & & 75 & 1 & \\
\hline & yes & 2 & $0.27(0.05-1.59)$ & 0.15 & 7 & $1.04(0.44-2.43)$ & 0.93 & 9 & $0.74(0.32-1.70)$ & 0.48 \\
\hline \multirow[t]{2}{*}{ Site of tuberculosis } & superficial & 13 & 1 & & 26 & 1 & & 39 & 1 & \\
\hline & deep & 19 & $1.48(0.68-3.20)$ & 0.32 & 16 & $0.46(0.24-0.86)$ & 0.02 & 35 & $0.62(0.38-1.03)$ & 0.07 \\
\hline \multirow[t]{4}{*}{ Specialty responsible for ending treatment } & pulmonary & 8 & 1 & & 34 & 1 & & 42 & 1 & \\
\hline & internal medicine & 7 & $6.85(2.24-20.97)$ & 0.001 & 5 & $1.09(0.32-3.72)$ & 0.90 & 12 & $1.89(0.86-4.14)$ & 0.11 \\
\hline & general medicine & 16 & $28.91(5.95-140.51)$ & $<0.001$ & 2 & $0.33(0.08-1.38)$ & 0.13 & 18 & $2.59(0.97-6.91)$ & 0.06 \\
\hline & other & 1 & $173.65(12.97-2325.22)$ & $<0.001$ & 1 & $1.99(0.79-5.01)$ & 0.14 & 2 & $5.27(1.48-18.73)$ & 0.01 \\
\hline \multirow[t]{2}{*}{ Pause of treatment } & no & 25 & 1 & & 22 & 1 & & 47 & 1 & \\
\hline & yes & 7 & $0.25(0.58-1.07)$ & 0.06 & 20 & $2.48(0.92-6.69)$ & 0.07 & 27 & $1.28(0.54-3.07)$ & 0.58 \\
\hline
\end{tabular}


Table 7: Multivariate analysis of 231 cases treated at least 24 hours, odds ratio for death or other unfavourable (transfer out, default, physician's decision to stop early) outcomes. (Continued)

\begin{tabular}{|c|c|c|c|c|c|c|c|c|c|c|}
\hline \multirow[t]{6}{*}{ Treatment group } & standard treatment $\mathrm{A}$ & 18 & 1 & & 17 & 1 & & 35 & 1 & \\
\hline & standard treatment B & 5 & $3.88(0.89-16.87)$ & 0.07 & 9 & $3.67(1.52-8.85)$ & 0.004 & 14 & $4.32(2.00-9.31)$ & $<0.001$ \\
\hline & standard treatment $C$ & 1 & $1.49(0.27-8.12)$ & 0.65 & 2 & $0.75(0.14-4.00)$ & 0.73 & 3 & $0.98(0.22-4.27)$ & 0.98 \\
\hline & standard treatment $\mathrm{D}$ & 1 & $1.26(0.10-16.51)$ & 0.86 & 5 & $2.52(0.50-12.80)$ & 0.27 & 6 & $2.46(0.76-8.00)$ & 0.13 \\
\hline & other combination & 6 & $5.06(1.13-22.57)$ & 0.03 & 9 & $1.47(0.35-6.24)$ & 0.60 & 15 & $2.02(0.56-7.31)$ & 0.28 \\
\hline & ineffective & 1 & $3.44(0.54-22.00)$ & 0.19 & 0 & 0 & $<0.001$ & 1 & $0.59(0.11-3.20)$ & 0.54 \\
\hline
\end{tabular}

Significant p-values are darkened.

Reference category is favourable treatment outcome. 
posed treatment duration is 12 months, and the case may therefore be categorized in the still on treatment category. There is also difficulty in acquiring culture samples late in the treatment for defining category cure. On the other hand, the proportion of tuberculosis of different extra-pulmonary organ locations is small in developed countries, and it would be impractical to have many different outcome assessment systems for pulmonary and extra-pulmonary disease.

The proportion of those being still on treatment at 12 months was $8.7 \%$, higher than the $3.9 \%$ in the pulmonary cohort [18]. The wide clinical diversity of extra-pulmonary TB can explain this partly, because the treatment time in the tuberculosis of central nervous system and bones is usually longer. It is also possible that the treatment of the wide variety of different forms of extra-pulmonary tuberculosis is even more unfamiliar to doctors than treating pulmonary tuberculosis.

There are no earlier studies of risk factors for unfavorable outcome in extra-pulmonary TB. Compared to those studies including all forms of disease, male sex, high age and immunosuppression were risk factors for death as has been previously reported $[6,8,29]$. Any other than a pulmonary specialty being responsible at the end of the treatment as a risk factor for death was noticed already in our pulmonary cohort [22], but other than standard combination of treatment as a risk factor was noticed only in this study. Even though our data allowed controlling for a range of comorbid states, it is possible that, in a patient population where half of the cases are older than 65 years, there could be more comorbidity in the subgroup that ends up being treated in internal medicine and geriatric services. In the univariate analysis there was a reverse association of death with the number of cases treated per year by the unit in charge of ending the treatment. However, this association did not remain an independent predictor in multivariable analysis, in contrast to our earlier study on pulmonary tuberculosis [22].

The finding that deep localization of TB was inversely associated with the risk of other unfavourable outcomes than death was new. It is probable that the efforts to ensure secure the continuity of treatment depend on the severity of TB disease. Superficial disease may be considered more benign. Our previous finding in pulmonary tuberculosis of the protective effect of history of earlier tuberculosis was not observed in this study population. The site of disease was not significantly associated with the risk of death. It seems that other factors like age and other comorbidities are more important risk factors of death, and the site of disease (deep or superficial) plays a smaller role.

In our previous analysis on pulmonary tuberculosis in the same two-year cohort of culture-verified tuberculosis, a case was defined as pulmonary using the case definition of NIDR, i.e. as a culture finding for $M$. tuberculosis in sputum or bronchoalveolar lavage (BAL), or as a culture finding for M. tuberculosis from another sample type in a case with sputum smear positive for acid fast bacilli. Now the analysis of the remaining part of the two-year cohort, revealed a group of 27 pulmonary cases with biopsy samples or gastric aspirate samples. This same bias existed probably in the statistics of NIDR, but it can be considered small compared to the total figures. The NIDR system is highly computerized, and a thorough evaluation of all TB cases is not possible with the resources available. However all cases in those less than 16 years of age are investigated in detail.

Due to the strictly controlled data collection process and high coverage, as reported previously [21], the data is highly representative. Only in 13 cases we could not trace enough patient record data to classify them. TB treatment recommendations and treatment organisation, the age distribution and the case fatality rate have all remained unchanged since the study period in 19951996, making the analysis and conclusions valid for the present.

\section{Conclusions}

The proportion of favourable outcome was far below the goal set by the WHO. Age and comorbidities, which play an important role in treatment success, are not usually analyzed for the routine outcome data. Comparisons in outcome between different countries should be made in cohort analyses with comprehensive data on comorbidities which are not collected with routine outcome surveillance systems. Separate reporting of treatment outcome in pulmonary and extra-pulmonary tuberculosis should be considered.

\section{Competing interests}

The authors declare that they have no competing interests.

\section{Authors' contributions}

TV checked the data, led the analysis and interpretation of the data, and prepared an initial draft of the manuscript. PH and JO performed the statistical analyses and contributed to drafting the manuscript. KL contributed to designing the study, analysis and interpretation of the data, and to drafting the manuscript. PR conceived of and coordinated the project, contributed to analysis and interpretation of the data, to drafting the manuscript, and critically revised the manuscript. All authors read and approved the final manuscript.

\section{Acknowledgements}

We thank MD Maarit Kokki for collecting data and Ms. Pirjo Turtiainen for technical assistance.

\section{Author Details}

'Department of Infectious Disease Surveillance and Control, National Institute for Health and Welfare, Mannerheimintie 166, 00300 Helsinki, Finland and ${ }^{2}$ Department of Respiratory Medicine, Turku University Hospital, Paimio Hospital, Alvar Aallon tie 275, 21540 Preitilä, Finland

Received: 23 December 2009 Accepted: 6 July 2010

Published: 6 July 2010 


\section{References}

1. World Health Organization: WHO Tuberculosis Programme: framework for effective tuberculosis control. In World Health Organization Document World Health Organization, Geneva; 1994. WHO/TB/94.179

2. Broekmans JF, Migliori GB, Rieder HL, Lees J, Ruutu P, Loddenkemper R, et al: European framework for tuberculosis control and elimination in countries with a low incidence. Recommendations of the World Health Organization (WHO), International Union Against Tuberculosis and Lung Disease (IUATLD) and Royal Netherlands Tuberculosis Association (KNCV) Working Group. Eur Respir J 2002, 19(4):765-775. World Health Organization International Union Against Tuberculosis and Lung Disease and Royal Netherlands Tuberculosis Association Working Group

3. Veen J, Raviglione M, Rieder HL, Migliori GB, Graf P, Grzemska M, et al: Standardized tuberculosis treatment outcome monitoring in Europe. Recommendations of a Working group of the World Health organisation (WHO) and the European Region of the International Union against Tuberculosis and Lung Disease (IUATLD) for uniform reporting by cohort analysis of treatment outcome in tuberculosis patients. Eur Respir J 1998, 12:505-510.

4. WHO IUATLD and KNCV: Revised international definitions in tuberculosis control. Int J Tuberc Lung Dis 2001, 5(3):213-215

5. EuroTB. Definitions for the WHO/EuroTB Joint Tuberculosis Data Collection 2007 [http://www.eurotb.org/data collection/english/ Definitions joint TB data collection form 2007.doc].

6. Lillebaek T, Poulsen S, Kok-Jensen A: Tuberculosis treatment in Denmark: treatment outcome for all Danish patients in 1992. Int J Tuberc Lung Dis 1999, 3(7):603-612.

7. Cayla JA, Caminero JA, Rey R, Lara N, Valles X, Galdos-Tanguis H, Working Group on Completion of Tuberculosis Treatment in Spain: Current status of treatment completion and fatality among tuberculosis patients in Spain. Int J Tuberc Lung Di 2004, 8(4):458-464.

8. Zellweger JP, Coulon P: Outcome of patients treated for tuberculosis in Vaud County, Switzerland. Int J Tuberc Lung Dis 1998, 2(5):372-377.

9. Wobeser W, Yuan L, Naus M, Tuberculosis Treatment Completion Study Group: Outcome of pulmonary tuberculosis treatment in the tertiary care setting -Toronto 1992/93. CMAJ: Canadian Medical Association Journal 1999, 160(6):789-794.

10. Chin DP, Cummings KC, Sciortino S, Snyder DC, Johnson LF, Westenhouse $J$, Royce SE: Progress and problems in achieving the United States national target for completion of antituberculosis treatment. Int J Tuberc Lung Dis 2000, 4(8):744-751.

11. Centis R, lanni A, Migliori GB: Evaluation of tuberculosis treatment results in Italy, report 1998. Tuberculosis section of the National AIPO Study Group on Infectious Disease and the SMIRA Group. Monaldi Arch Chest Dis 2000, 55(4):293-298.

12. Ormerod LP, Horsfield N, Green RM: Tuberculosis treatment outcome monitoring: Blackburn 1988-2000. Int J Tuberc Lung Dis 2002, 6(8):662-665

13. Trnka L, Daňkova D, Krejbich F: Is quarterly cohort analysis useful for assessing treatment outcomes in a low incidence country? Int J Tuberc Lung Dis 2001, 5(3):250-256.

14. Helbling P, Medinger C, Altpeter E, Raeber PA, Beeli D, Zellweger JP: Outcome of treatment of pulmonary tuberculosis in Switzerland in 1996. Swiss Med Wkly 2002, 132(35-36):517-522.

15. Ormerod LP, Prescott RJ: The management of pulmonary and lymph node tuberculosis notified in England and Wales in 1998. Clin Med 2003, 3(1):57-61.

16. Faustini A, Hall AJ, Perucci CA: Tuberculosis treatment outcomes in Europe: a systematic review. Eur Respir J 2005, 26:503-510.

17. Farah M, Tverdall A, Steen T, Heldall E, Brantsaeter A, Bjune G: Treatment outcome of new culture positive pulmonary tuberculosis in Norway. BMC Public Health 2005, 5:14.

18. Vasankari T, Kokki M, Holmström P, Liippo K, Sarna S, Ruutu P: Great diversity of tuberculosis treatment in Finland. Euro Surveill 2007, 12:17-21.

19. EuroTB and the national coordinators for tuberculosis surveillance in the WHO European Region: Surveillance of tuberculosis in Europe. Report on tuberculosis cases notified in 2006. Institut de veille sanitaire, SaintMaurice, France; 2008

20. Ditah IC, Reacher M, Palmer C, Watson JM, Innes J, Kruijshaar ME, Luma HN, Abubakar I: Monitoring tuberculosis treatment outcome: analysis of national surveillance data from a clinical perspective. Thorax 2008, 63:440-446.

21. Kokki M, Holmström P, Ruutu P: High sensivity for tuberculosis in a laboratory-based national integrated infectious disease surveillance system in Finland. Euro Surveill 2005, 10:90-93.

22. Vasankari T, Holmström P, Ollgren J, Liippo K, Kokki M, Ruutu P: Risk factors for poor tuberculosis treatment outcome in Finland: a cohort study. BMC Public Health 2007, 7:291

23. Lääkintöhallitus: Tuberkuloosi ja sen lääkehoito. Kapseli 1985. Finnish National Board of Health. Tuberculosis and its treatment 15 Lääkintöhallituksen julkaisu (in Finnish)

24. World Health Organization Tuberculosis Unit Division of Communicable Disease: Guidelines for tuberculosis treatment in adults and children in National Tuberculosis Programmes. :161. WHO/TB/91

25. American Thoracic Society: Treatment of tuberculosis and tuberculosis infection in adults and children. Am Rev Resp Dis 1986, 134:355-363.

26. Joint Tuberculosis Committee of the British Thoracic Society: Chemotherapy and management of tuberculosis in the United Kingdom: recommendations. Thorax 1990, 45:403-408.

27. Davies PDO: Clinical tuberculosis. London, MacMillan Education; 1994.

28. Tala E: Tuberkuloosin lääkehoito ja -profylaksia. Tuberculosis treatment and prophylaxis. Duodecim 1993, 109:69-75. in Finnish

29. Falzon D, Le Strat Y, Belghiti F, Infuso A, EuroTB Correspondents: Exploring the determinants of treatment success for tuberculosis cases in Europe. Int J Tuberc Lung Dis 2005, 9:1224-1229.

\section{Pre-publication history}

The pre-publication history for this paper can be accessed here: http://www.biomedcentral.com/1471-2458/10/399/prepub

doi: 10.1186/1471-2458-10-399

Cite this article as: Vasankari et al., Treatment outcome of extra-pulmonary tuberculosis in Finland: a cohort study BMC Public Health 2010, 10:399

\section{Submit your next manuscript to BioMed Central and take full advantage of:}

- Convenient online submission

- Thorough peer review

- No space constraints or color figure charges

- Immediate publication on acceptance

- Inclusion in PubMed, CAS, Scopus and Google Scholar

- Research which is freely available for redistribution 